\title{
INFLUENCE OF PRIMARY HOMOGENIZATION STEP ON MICROFLUIDIZED EMULSIONS FORMULATED WITH THYME OIL AND APPYCLEAN 6548
}

\author{
Luis A. Trujillo-Cayado ${ }^{a}, M_{\text {Carmen Alfaro }}{ }^{\star *}$, Jenifer Santos ${ }^{a}$, Nuria Calero ${ }^{a}$, and José
}

Muñoz ${ }^{\mathrm{a}}$

a Departamento de Ingeniería Química, Facultad de Química, Universidad de Sevilla, C/

P. García González, 1, E41012, Sevilla, Spain.

* Corresponding author. M Carmen Alfaro Rodríguez; Tel.: +34 954 557180; fax: +34

954 556447; E-mail address: alfaro@us.es

\section{ABSTRACT}

This contribution deals with the development of emulsions formulated using thyme essential oil and a new biomass-derived surfactant. In addition, this work extends our knowledge concerning the factors that can influence stability and droplet size distributions of microfluidized emulsions, such as the geometry of the rotor-stator used and the homogenization rate in the primary homogenization. Stable thyme oil-in-water emulsions (30 wt\%) containing submicron droplets were formed. Interestingly, laser diffraction results reveal that mean droplet sizes are mainly controlled by homogenization rates and polydispersity by the rotor-stator geometry used in the first step of homogenization. In addition, higher droplet sizes for pre-emulsions seem to be a key factor in order to reduce both the degree of recoalescence and the size of the droplets in the second homogenization step. Furthermore, higher droplet sizes in the preemulsion favour higher physical stability of the final emulsions. Finally, this research highlights the importance of controlling primary homogenization conditions for the physical stability of microfluidized emulsions that contain natural ingredients.

Keywords: Droplet size; emulsion; Microfluidizer; physical stability; thyme oil

\section{INTRODUCTION}

There is a growing interest in the use of essential oils, like thyme oil, due to their antimicrobial activity and biocompatible properties. These properties make them widely used in fields such as food, pharmaceutical and cosmetics. In addition, these natural resources have been recognized as GRAS (Generally Recognized As Safe) by U.S. Food and Drug Administration [1], which makes them the most promising natural antimicrobials. Thyme oil, obtained from Thymus vulgaris $L$, is divided into two different 
classes: red and white. Red thyme oil is the product of the distillation of dried thyme leaves while white is obtained from red thyme oil re-distillation [2]. The potential application of white thyme oil as a food preservative to replace synthetic chemicals, which are potentially toxic to humans, has been demonstrated [3]. Nevertheless, the major disadvantage of utilizing essential oils is their high volatility and their tendency to oxidise. Emulsion-based systems are a very attractive way to increase their stability by reducing their volatility and conserving their biological characteristics [4]. Oil-in-water emulsions are systems consisting of oil phase dispersed in aqueous phase, usually in the form of droplets. These systems are important vehicles for the delivery of hydrophobic bioactive compounds and have found a wide range of applications in many industries including food, pharmacy, cosmetics and agrochemistry [5-7].

Emulsions need an emulsifier since they are thermodynamically unstable. In recent years, the use of green surfactants has been attracting attention. Appyclean 6548, a new surfactant derived from wheat waste (alkyl poly pentoside), fulfils all the requirements to be considered a green surfactant; namely it is derived from renewable resource and manufactured by environmentally friendly processes. In fact, this emulsifier possesses the ECOCERT certification.

In order to produce emulsions with specific physicochemical and functional properties, controlling the droplet size distribution is required. Droplet size distributions are strongly influenced by the emulsification method and conditions used. Emulsions can be developed using low-energy and high-energy approaches. However, the latter are more likely to be used in the food or cosmetic field since their scale-up is easier and the equipment is more readily available. A multitude of homogenizers, such as rotor-stators, ultrasounds, colloid mills or high-pressure valve homogenizers, can be used to prepare these systems. Emulsions can be prepared in two steps: primary and secondary homogenization. The aim of the primary homogenization is to create droplets of dispersed phase such that a coarse emulsion is formed. The goal of the second step (secondary homogenization) is to reduce the size of pre-existing droplets, which usually involves the use of a different homogenizer. There are several studies concerning the influence of homogenization rate and the device used on physical stability, rheology and droplet size distribution for emulsion-based systems [8-13]. One homogenizer used in the second step that has received a lot of attention recently is the Microfluidizer, due to several results that suggest its use provides narrower distributions at smaller droplet sizes [14,15]. Some research has been carried out in order to extend our knowledge about the influence of the number of cycles and homogenization pressure in Microfluidizers $[9,16,17]$. Furthermore, the comparison between using single- or dual- 
channel microfluidizers and one or two interaction chambers have been reported [1820]. The main novelty of this research is the study of the influence of the pre-emulsion properties on the droplet size distribution and physical stability of the final emulsions. For this reason, the present work aims to provide an exhaustive study of the influence of the primary homogenization on microfluidized emulsion properties. On top of that, a further aim of this research was to obtain stable ecological emulsions of thyme oil formulated with an emulsifier obtained from wheat. The results of this study could be useful to design and develop functional oil-in-water emulsions.

\section{MATERIALS AND METHODS}

\section{Materials}

30 wt $\%$ oil-in-water emulsions with a surfactant (Appyclean 6548) concentration of 3 wt\% were prepared using thyme essential oil as dispersed phase. Thyme oil (Thymus vulgaris) was purchased from Sigma Aldrich. The emulsifier (Appyclean 6548) used was an alkyl poly pentoside provided by Wheatoleo. This non-ionic surfactant is solid and immiscible in water at room temperature. Deionised water obtained from a water purification system was used for the preparation of all samples. Sodium azide $(0.1 \mathrm{wt} \%)$ was added to the formulation in order to inhibit the growth of microorganisms. All of the chemicals were used as received.

\section{Preparation of oil-in-water emulsions}

The surfactant was dispersed into the oil phase. $5.55 \mathrm{~g}$ of Appyclean 6548 was added to $55.5 \mathrm{~g}$ of Thyme essential oil for emulsion batches of $185 \mathrm{~g}$. Then, the surfactant was melted and dissolved in the essential oil at $70^{\circ} \mathrm{C}$ in a laboratory oven according to the supplier's instructions. The continuous phase was prepared by dissolving $0.185 \mathrm{~g}$ of sodium azide in the corresponding amount of water.

Two different rotor-stator devices (Ultraturrax T50 with a S50NG45F dispersion unit and Silverson L5M equipped with an emulsor mesh screen) were used for the primary homogenization. Pre-emulsions were produced by adding the oil phase at $20 \stackrel{\circ}{C}$ to the continuous phase (deionised water and sodium azide), also at $20 \stackrel{\circ}{ } \mathrm{C}$, using a syringe pump at a constant flow rate of $21.67 \mathrm{~mL} / \mathrm{min}$ during $180 \mathrm{~s}$, and then were homogenized for an additional $30 \mathrm{~s}$. The homogenization speed was fixed at 2000, 4000 or $6000 \mathrm{rpm}$ using Ultraturrax T50 or Silverson L5M, so three batches of six different pre-emulsions were developed. The initial and final temperatures of the emulsion and the amperage were measured during the primary emulsification process in order to determine the power density. 
The secondary homogenization was performed using a Microfluidizer M110P (interaction chambers F12Y) at 2500 psi (172 bar) for one pass. These conditions were chosen in order to highlight the importance and influence of the primary homogenization for the development of oil-in-water emulsions by microfluidization. The outlet sample tube of the Microfluidizer was cooled with water at $20^{\circ} \mathrm{C}$. The $\mathrm{pH}$ values for the continuous phases and the final emulsions were 5.94 and 6.42, respectively

\section{Droplet size distributions of emulsions}

The droplet size distribution and mean droplet sizes were determined using a Malvern Mastersizer $X$. Volumetric mean diameter $\left(D_{4,3}\right)$ was used to compare the droplet sizes of different emulsions:

$$
D_{4,3}=\frac{\sum_{i=1}^{N} n_{i} d_{i}^{4}}{\sum_{i=1}^{N} n_{i} d_{i}^{3}} \quad \text { Eq. }(1)
$$

where $d_{i}$ is the droplet diameter, $N$ is the total number of droplets and $n_{i}$ is the number of droplets having a diameter $\mathrm{d}_{\mathrm{i}}$. Moreover, span was used to study the distribution width of droplet sizes:

$$
\operatorname{span}=\frac{D(v, 0.9)-D(v, 0.1)}{D(v, 0.5)} \quad \text { Eq. }(2)
$$

where $D(v, 0.9), D(v, 0.5), D(v, 0.1)$ are diameters at $90 \%, 50 \%$ and $10 \%$, respectively, of cumulative volume. The absorption and refraction indexes used for the continuous medium (water) were 0.1 and 1 , respectively, whereas the refraction index for the dispersed phase (thyme oil) was 1.50. Droplet size distributions were obtained using a polydisperse analysis. The influence of aging time on droplet size distributions was studied during 20 days after preparation to analyze and quantify coalescence/Ostwald ripening effects.

\section{Analysis of emulsion physical stability}

The physical stability of emulsions whose pre-emulsions were obtained with different emulsification methods was studied and quantified by means of multiple light scattering measurements (Turbiscan Lab Expert) at $25^{\circ} \mathrm{C}$. The results are presented in the form of curves which show intensities of backscattering in reference mode (delta-backscattering, $\left.\Delta \mathrm{BS} \%=\mathrm{BS}_{\mathrm{t}} \%-\mathrm{BS}_{0} \%\right)$ as a function of time and height. The Turbiscan Stability Index (TSI) has been used for the comparison and estimation of the emulsion stability. The value of this parameter was calculated with the special computer program using the equation:

$$
T S I=\sum_{i} \frac{\sum_{h}\left|\operatorname{scan}_{i}-\operatorname{scan}_{i-1}\right|}{H} \quad \text { Eq. (3) }
$$


Where $\operatorname{scan}_{i}$ is the average backscattering for each time (i) of measurement, scan $_{\mathrm{i}-1}$ is the average backscattering for the (i-1) time of measurement and $\mathrm{H}$ is the number of scans carried out on the sample.

\section{Flow Curves}

Flow curves for pre-emulsions and emulsions were obtained by means a controlledstress rheometer, CS Haake-MARS (Thermo), and a sandblasted Z20 coaxial cylinder

$141(\mathrm{Ri}=1 \mathrm{~cm}, \mathrm{Re} / \mathrm{Ri}=1.085)$ at 24 hours of aging time and they were performed at $25^{\circ} \mathrm{C}$.

142 A step-wise protocol in the 0.1-20 Pa shear stress range was applied. All samples 143 showed Newtonian behaviour which was fitted to Newton's law.

144 All measurements were done in duplicate and the values shown are the average of the two replicates.

\section{RESULTS AND DISCUSSION}

147 Figure 1 illustrates the power density $\left(P_{v}\right)$ as a function of the residence time for five replicates of the pre-emulsion processed at 2000 rpm using a Silverson L5M rotor-stator device. A decrease in power density values with homogenization time is clearly observed. The energy density $\left(E_{v}\right)$ or mechanical energy input per unit of dispersing volume for all pre-emulsions was calculated using the power density values by means of the following equation [21,22]:

$$
E \mathrm{v}=\int \operatorname{Pv}(\mathrm{t}) d t=\int \frac{W(N, t)}{\frac{M_{C}}{\rho_{c}(t)}+\frac{M_{0}}{\rho_{0}(t)}} d t
$$

Where $E_{v}$ is the energy density or energy consumption, $P_{v}$ is the power density, $W$ is the electrical power consumption, $M_{C}$ and $M_{0}$ are the masses of the continuous and dispersed phases respectively and $\rho_{c}$ and $\rho_{0}$ are the densities of the continuous and dispersed phases respectively, $\mathrm{N}$ is the homogenization rate and $\mathrm{t}$ is the homogenization time. Both densities are time dependent due to the increase in temperature during emulsification.

The values of $E_{v}$ for all pre-emulsions are shown in table 1. It should be noted that, as expected, there is an increment in the energy consumption with homogenization rate for both rotor-stator devices. Interestingly, energy consumption values obtained for the preemulsions developed using an Ultraturrax T50 are much higher than those obtained for the samples processed with the Silverson L5M rotor-stator device. This fact is probably due to the differences between the geometries of both rotor-stator devices [23]. The resulting droplet size distributions (DSDs) for these pre-emulsions are shown in figure 2. 
167 Higher homogenization rates in both rotor stator devices lead to the production of smaller 168 droplets (Table 1). Pre-emulsions developed at $2000 \mathrm{rpm}$ in both rotor-stator devices 169 show bimodal DSDs. In contrast, monomodal distributions were observed for emulsions 170 processed above $2000 \mathrm{rpm}$ in both homogenizers. This fact reveals the importance of 171 higher homogenization rates/energy input in order to reduce the second peak of the 172 distribution and obtain a monomodal DSD. It is important to note that the use of different 173 types of rotor-stator did not significantly affect volumetric diameter at the same 174 homogenization rate. Although the energy consumption values at the same 175 homogenization rate are different for Silverson L5M and Ultraturrax T50, similar droplet 176 mean diameters are detected. This result suggests the higher efficiency of Silverson

177 L5M. Even so, although the mean droplet sizes are similar, some slight differences in 178 DSD can be observed between the pre-emulsions with SL5M and UT50 at the same 179 homogenization rate. Thyme essential oil-in-water emulsions processed in Silverson 180 L5M tend to possess narrower DSD. In these terms, the existence of little holes in 181 Silverson L5M favours the existence of jets in the velocity profile contrary to UT50, as 182 previously reported by Ozcan-Tas et al., 2011[24]. It may be the reason why the 183 polydispersity of emulsions prepared with SIlverson L5M is lower than those developed 184 using UT50.

185 Figure 3 shows, by way of example, the variation in Backscattering in mode reference $186(\triangle \mathrm{BS} \%)$ as a function of the height of the measuring cell with aging time for pre-emulsions 187 developed at $2000 \mathrm{rpm}$ with Silverson L5M. All pre-emulsions follow the same 188 destabilization trend. A marked decrease in BS in the lower zone of the measuring cell 189 is observed during the first 24 hours. This reduction extends over the whole measuring 190 cell with aging time. This fact is a clear indication of a creaming process, such as 191 commonly occurs in dispersed systems such as emulsions [25,26]. This destabilization 192 mechanism is favoured by the low viscosity of these pre-emulsions (3.71-5.25 mPa.s) 193 and the high droplet sizes [27]. In order to improve the stability of these emulsions 194 formulated with thyme oil and Appyclean 6548, a secondary homogenization was carried 195 out.

196 The DSD of the final emulsions is shown in Figure 4. All microfluidized emulsions exhibit 197 two populations of droplets, which is probably due to an excess of energy input 198 (recoalescence). This fact occurs often in emulsions prepared in high pressure 199 homogenizers and Microfluidizers $[17,28]$. In order to analyse the recoalescence for 200 emulsions studied, the data of the second peak were fitted to a Gaussian model:

$$
y=y_{0}+A e^{\frac{-\left(x-x_{c}\right)^{2}}{2 w^{2}}} \quad \text { Eq. (5) }
$$


202 where $y_{0}$ is the offset, $x_{c}$ the centre of the peak, $w$ the width of the peak and $A$ the 203 amplitude.

204 One factor which should be noted is the low degree of recoalescence observed in microfluidized emulsions whose pre-emulsions were prepared at the lowest homogenization rate $(2000 \mathrm{rpm})$. This fact can be deduced from the area of the second peak (table 2), which is lower for emulsions whose pre-emulsions were prepared at 2000 rpm. In addition, microfluidized emulsions processed in UT50 showed a higher degree of recoalescence than those obtained using SL5M, evidence of which can be seen in the larger area or higher median value of the second peak (table 2). These facts support the aforementioned hypothesis concerning over-processing. Moreover, all results suggest that for thyme essential oil-in-water emulsions formulated with Appyclean 6548 the homogenization rate in the primary homogenization and, therefore the droplet size of the pre-emulsion, is a key factor for final emulsions. It seems that bigger droplets in the first step of homogenization could favour the break-up of the droplets inside the Microfluidizer chamber. Accordingly, a lower homogenization rate in pre-emulsion, implying higher droplet sizes, is recommended in order not only to reduce recoalescence in the Microfluidizer but also to obtain final emulsions with better properties. This fact is evident, taking into account the volumetric diameter and span values for final emulsions (figure 5). As can be observed in figure 5, there is a noticeable increase in droplet size and polydispersity with homogenization rate applied in the primary homogenization. Hence, although higher droplet size in the first step of homogenization could seem a drawback, results reveal that the break-up of droplets is favoured and recoalescence is less probable.

To study the physical stability of emulsions, the backscattering profiles were analysed at different storage times in reference mode allowing a better display of the destabilization processes. Figure $6 \mathrm{~A}$ and $6 \mathrm{~B}$ illustrate the variation of delta-backscattering $(\triangle \mathrm{BS} \%)$ versus measuring cell height as a function of aging time for emulsion with pre-emulsion processed using Ultraturrax T50 at 2000 and 6000 rpm. Firstly, it should be noted that the microfluidized emulsions possess higher physical stability than pre-emulsions (see figure 3), as expected [29]. Final emulsions showed a marked drop in backscattering (a peak in $\triangle \mathrm{BS}$ curves) in the lower zone of the measuring cell $(0-5 \mathrm{~mm})$, which is typical of migration of droplets; namely a destabilization mechanism by creaming occurs. All emulsions studied underwent creaming at similar rates $(0.048-0.052 \mathrm{~mm} /$ day) and intensities, as can be observed in figures $6 \mathrm{~A}$ and $6 \mathrm{~B}$. This instability is clearly related to the low Newtonian viscosity they present (7.78-8.80 $\mathrm{mPa} \cdot \mathrm{s})$ [27]. Additionally, there is also a decrease in the BS intensity in the middle zone of the tube, indicative of an 
increment in mean droplet sizes $[6,26]$. The decrease in BS intensity in the middle zone is more marked for the emulsion processed at $6000 \mathrm{rpm}$ (see figure 6B). This behaviour may be related to flocculation, coalescence or Ostwald ripening. In order to discern between these destabilization processes as well as quantify the destabilization mechanism that provokes this variation, the evolution over time of droplet size distributions, droplet mean diameters and span was analysed.

Figure 7 shows the droplet size distributions with aging time for the microfluidized emulsion whose pre-emulsion was developed using Ultraturrax T50 at 2000 and 6000 rpm. This figure illustrates a shift of DSD towards higher droplet sizes and a reduction in polydispersity for both emulsions. It is more clearly observed for $6000 \mathrm{rpm}$ emulsion, which is totally consistent with the results obtained from laser diffraction measurements. This behaviour suggests that the increase in mean diameters observed with the multiple light scattering technique is due to a destabilization mechanism by Ostwald ripening [30]. This result is consistent with works reported by other authors and it is typically observed in essential oil-in-water emulsions [31,32]. All emulsions presented an increase in volumetric mean diameter and a reduction in span, which is shown in figure 8 . The variations of Volumetric diameter and span values from day 20 to day 1 were calculated as follows:

$$
\Delta D_{4,3}=\frac{D_{4,3 \text { day } 20}-D_{4,3 \text { day } 1}}{D_{4,3 \text { day } 1}} \text { Eq. (6) }
$$

$$
\Delta \text { span }=\frac{\text { span }_{\text {day } 20}-\operatorname{span}_{\text {day } 1}}{\operatorname{span}_{\text {day } 1}} \text { Eq. (7) }
$$

A clear influence of both the primary homogenization rate and the rotor-stator device used for the development of the pre-emulsions on the evolution of both the volumetric mean diameter and span of microfluidized emulsions can be observed. In this sense, emulsions developed at higher homogenization rates presented the major variations in both parameters and emulsions processed with SL5M showed smaller variations in droplet sizes and span than their counterparts processed using UT50. These facts are related to the higher polydispersity these emulsions exhibited at 24 hours (see figure 4), i.e. more polydispersity favours destabilization by Ostwald ripening [33]. Turbiscan Stability Index (TSI) values as a function of aging time for all thyme oil microfluidized emulsions are shown in figure 9. This parameter, obtained in the 0-30 $\mathrm{mm}$ zone, allows global physical stability (considering all destabilization mechanisms) to be analysed for these dispersed systems. High values of TSI involve poor physical stability. In this way, the influence of the homogenization rate used in the primary homogenization 
on the final emulsion physical stability is demonstrated. Two trends can be clearly observed, as expected. On the one hand, the use of a lower homogenization rate during the primary homogenization allowed lower TSI values to be obtained. On the other hand, microfluidized emulsion whose pre-emulsion was prepared in Silverson L5M showed better physical stability than those whose pre-emulsion was developed using Ultraturrax T50. These facts are related to the aforementioned differences in polydispersity, i.e. higher polydispersity involves higher TSI values. Hence, the microfluidized emulsion whose primary homogenization was in Silverson L5M at the lowest homogenization rate presented the best global physical stability and the lowest droplet size and polydispersity. This fact demonstrates the necessity for a pre-emulsion with a relatively large droplet size in order to allow the Microfluidizer to play its role in forming finer emulsions.

\section{CONCLUSIONS}

Stable and concentrated thyme oil-in-water emulsions formulated with a biomassderived surfactant obtained from renewable resources have been developed. No significant differences in droplet sizes for pre-emulsions prepared using Silverson L5M or Ultraturrax T50 at the same homogenization rate were observed. However, the energy consumption for Ultraturrax T50 was much higher than that of Silverson L5M, suggesting the greater efficiency of the latter. Results obtained for these pre-emulsions indicate that mean droplet sizes are mainly controlled by homogenization rates and polydispersity by rotor-stator geometry. All pre-emulsions showed low physical stability involving a creaming destabilization process due to their high mean droplet sizes, high polydispersity and low viscosity.

Microfluidized emulsions showed submicron mean droplet sizes but a recoalescence process was observed. This effect was favoured by higher homogenization rates and the use of Ultraturrax T50 in the primary homogenization. Therefore, the droplet size distribution of the pre-emulsions is a key factor that strongly influences the droplet size distribution of the final emulsions. Higher mean droplet sizes for pre-emulsions could favour the break-up of the droplets inside the high-pressure homogenizer chamber, allowing lower droplet size in microfluidized emulsions to be obtained. Hence, the coarse emulsion developed using Silverson L5M at $2000 \mathrm{rpm}$ produced the microfluidized emulsion with the narrowest droplet size distribution and the lowest mean droplet sizes. All microfluidized emulsions presented higher physical stability than those developed only with a rotor-stator device. However, a creaming process and an increase in droplet size were observed in final emulsions. These variations in droplet sizes involved a 
This phenomenon was more marked for those microfluidized emulsions whose preemulsions were developed at higher homogenization rates.

This work demonstrates that a tight control of the primary homogenization conditions in the development of microfluidized emulsions is required. Results obtained from this work can be useful for further design and fabrication of functional emulsions suitable for utilization within the food, chemical, pharmaceutical, personal care, and other industries.

\section{ACKOWLEDGMENTS}

The financial support received (Project CTQ2015-70700-P) from the Spanish Ministerio de Economía y Competitividad and from the European Commission (FEDER Programme) is kindly acknowledged.

\section{References}

[1] USA, Code of Federal Regulations, Title 21 Food and drugs, Chapter I Food and Drug Administration Department of Health and Human Services, Subchapter BFood for Human Consumption, Part 182-Substances Generally Recognized as Safe. Sec. 182.20 Essential oils (2011).

[2] I.M. Martins, S. N. Rodrigues, F. Barreiro, A. E. Rodrigues, J. Microencapsul. 26(8) (2012) 667-675.

[3] A.A. Dobre, V. Gagiu, N. Petru, Rom. Biotechnol. Lett. 16(6) (2011) 119-25.

[4] S. Rodríguez-Rojo, S. Varona, M. Núñez,, M.J. Cocero, Ind. Crops Prod. 37(1) (2012) 137-40.

[5] K.C. Powell, R. Damitz, A. Chauhan, Int. J. Pharm. 521(1) (2017) 8-18.

[6] L.A. Trujillo-Cayado, M.C. Alfaro, J. Muñoz, Colloids Surfaces A Physicochem. Eng. Asp. 536 (2018) 198-203.

[7] M. Matos, A. Laca, F. Rea, O. Iglesias, M. Rayner, G. Gutiérrez, J. Food Eng. 222 (2018) 207-17.

[8] S. Aben, C. Holtze, T. Tadros, P. Schurtenberger, Langmuir 28(21) (2012) 7967-75.

[9] J. Santos, L.A. Trujillo-Cayado, N. Calero, M.C. Alfaro, J. Muñoz, J. Ind. Eng. Chem. (2016).

[10] S.M. Jafari, Y. He, B. Bhandari, Eur. Food Res. Technol. 225(5-6) (2007) 73341.

[11] J. Santos, N. Calero, J. Munoz, RSC Adv. 62(6) (2016) 57563-8.

[12] S. Mahdi Jafari,, Y. He,, B. Bhandari, Int. J. Food Prop. 9(3) (2006) 475-85.

[13] U. El-Jaby, M. Cunningham, T.F.L. McKenna, Ind. Eng. Chem. Res. 48(22) (2009) 10147-51. 
[14] J.M. Perrier-Cornet, P. Marie, P. Gervais, J. Food Eng. 66(2) (2005) 211-7.

[15] K.B. Strawbridge, E. Ray, F.R. Hallett, S.M. Tosh, D.G. Dalgleish, J. Colloid Interface Sci. 171(2) (1995) 392-8.

[16] S.S. Galooyak, B. Dabir, J. Food Sci. Technol. 52(5) (2015) 2558-71.

[17] L.A. Trujillo-Cayado, J. Santos, M.C. Alfaro, N. Calero, J. Muñoz, Ind. Eng. Chem. Res. 55(27) (2016) 7259-66.

[18] L.A. Trujillo-Cayado, J. Santos, P. Ramírez, M.C. Alfaro, J. Muñoz, J. Clean. Prod. 178 (2018) 723-30.

[19] L. Bai, D.J. McClements, J. Colloid Interface Sci. 466 (2016) 206-12.

[20] L. Bai, S. Huan, J. Gu, D.J. McClements, Food Hydrocoll. 61 (2016) 703-11.

[21] H. Schubert, K. Ax, O. Behrend, Trends Food Sci. Technol. 14(1-2) (2003) 916.

[22] P. Walstra, P.E.A. Smulders, Mod. Asp. Emuls. Sci. (1998) 56-99.

[23] H. Schubert, R. Engel, Chem. Eng. Res. Des. 82(9) (2004) 1137-43.

[24] G. Özcan-Taşkin, D. Kubicki, G. Padron, Can. J. Chem. Eng. 89(5) (2011) 1005-17. 10.1002/cjce.20553.

[25] J. Santos, N. Calero, J. Muñoz, Chem. Eng. Res. Des. 100 (2015) 261-7.

[26] O. Mengual, G. Meunier, I. Cayré, K. Puech, P. Snabre, Talanta 50(2) (1999) 445-56.

[27] D.J. McClements, Crit. Rev. Food Sci. Nutr. 47(7) (2007) 611-49.

[28] S.M. Jafari, E. Assadpoor, Y. He,, B. Bhandari, Food Hydrocoll. 22(7) (2008) 1191-202. 10.1016/j.foodhyd.2007.09.006.

[29] D.J. McClements, Food emulsions: principles, practices, and techniques, CRC press, 2015.

[30] E. Nazarzadeh, T. Anthonypillai, S. Sajjadi, J. Colloid Interface Sci. 397 (2013) 154-62.

[31] Y. Chang, L. McLandsborough, D.J. McClements, Food Chem. 172 (2015) 298304.

[32] V. Ryu, D.J. McClements, M.G. Corradini, L. McLandsborough, Food Chem. 245(September 2017) (2018) 104-11. 10.1016/j.foodchem.2017.10.084.

[33] T.J. Wooster, M. Golding, P. Sanguansri, Langmuir 24(22) (2008) 12758-65. 
397

398

399

400

401

402

403

404

405

406

407

408

409

410

411

Tables

Table 1.- Energy consumption $\left(E_{v}\right)$ and volumetric mean diameter $\left(D_{4,3}\right)$ as a function of homogenization rate for all emulsions processed using only a rotor-stator device

\begin{tabular}{|c|c|c|c|}
\hline $\begin{array}{l}\text { Rotor-stator } \\
\text { device }\end{array}$ & $\begin{array}{l}\text { Homogenization } \\
\text { rate }(\mathrm{rpm})\end{array}$ & $\begin{array}{c}E_{v} \\
\left(k J \cdot m^{-3}\right)\end{array}$ & $\begin{array}{l}D_{4,3} \\
(\mu \mathrm{m})\end{array}$ \\
\hline \multirow{3}{*}{$\begin{array}{l}\text { UltraTurrax T50 } \\
\quad \text { (UT50) }\end{array}$} & 2000 & $349.50 \pm 2.89$ & $6.36 \pm 0.44$ \\
\hline & 4000 & $382.02 \pm 8.87$ & $2.56 \pm 0.15$ \\
\hline & 6000 & $442.77 \pm 2.74$ & $2.02 \pm 0.11$ \\
\hline \multirow{3}{*}{$\begin{array}{l}\text { Silverson L5M } \\
\quad(\mathrm{SL} 5 \mathrm{M})\end{array}$} & 2000 & $126.31 \pm 2.22$ & $7.01 \pm 0.52$ \\
\hline & 4000 & $141.14 \pm 3.21$ & $2.58 \pm 0.13$ \\
\hline & 6000 & $163.67 \pm 4.58$ & $1.84 \pm 0.10$ \\
\hline
\end{tabular}

Table 2. Centre and area of the second peaks of the DSD for microfluidized emulsions. Parameters obtained from Gaussian model.

\begin{tabular}{|c|c|c|c|}
\hline $\begin{array}{c}\text { Rotor-stator } \\
\text { device }\end{array}$ & $\begin{array}{c}\text { Homogenization } \\
\text { rate }(\mathbf{r p m})\end{array}$ & $\mathbf{X}_{\mathrm{c}}(\boldsymbol{\mu m})$ & $\begin{array}{c}\text { Peak Area } \\
(\% \cdot \mu \mathrm{m})\end{array}$ \\
\hline \multirow{2}{*}{$\begin{array}{c}\text { UltraTurrax T50 } \\
(\text { UT50) }\end{array}$} & 2000 & 3.57 & 5.06 \\
\cline { 2 - 4 } & 4000 & 2.85 & 10.91 \\
\hline \multirow{2}{*}{$\begin{array}{c}\text { Silverson L5M } \\
\text { (SL5M) }\end{array}$} & 6000 & 2.94 & 12.30 \\
\cline { 2 - 4 } & 2000 & 2.05 & 1.57 \\
\cline { 2 - 4 } & 6000 & 2.12 & 10.56 \\
\hline
\end{tabular}

(a)

ais




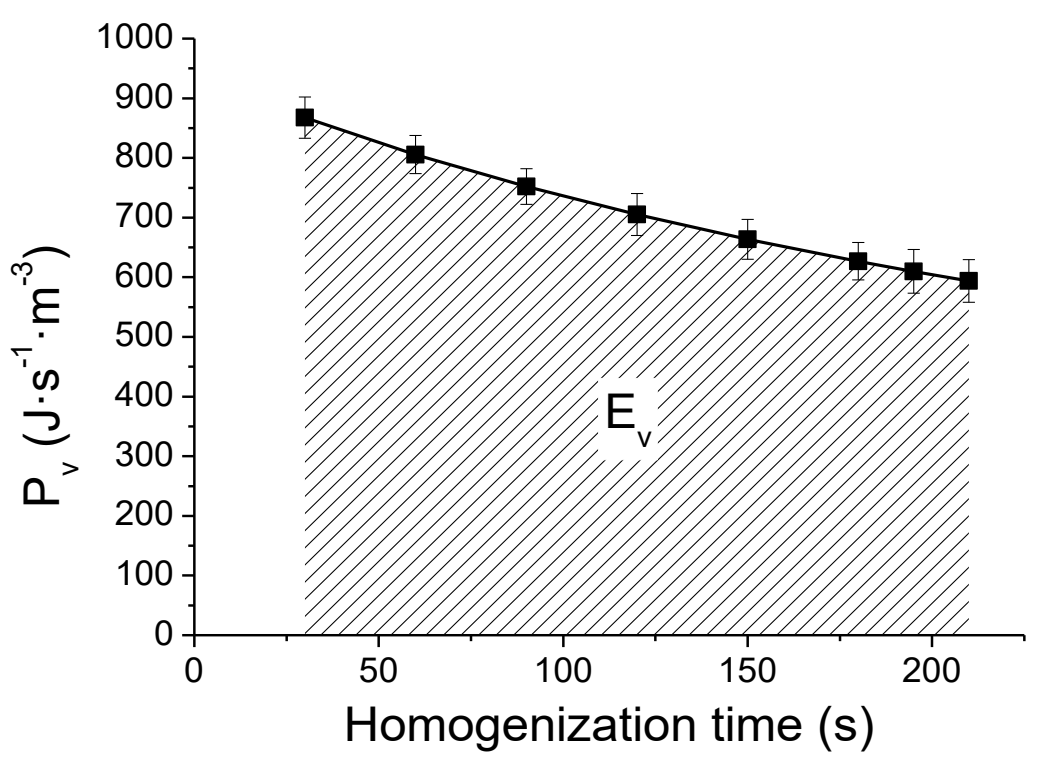

Figure 1.- Power density $\left(P_{v}\right)$ for five replicates of the emulsions processed using a 416 Silverson L5M at $2000 \mathrm{rpm}$ as a function of homogenization time. Vertical bars indicate 417 standard deviation data

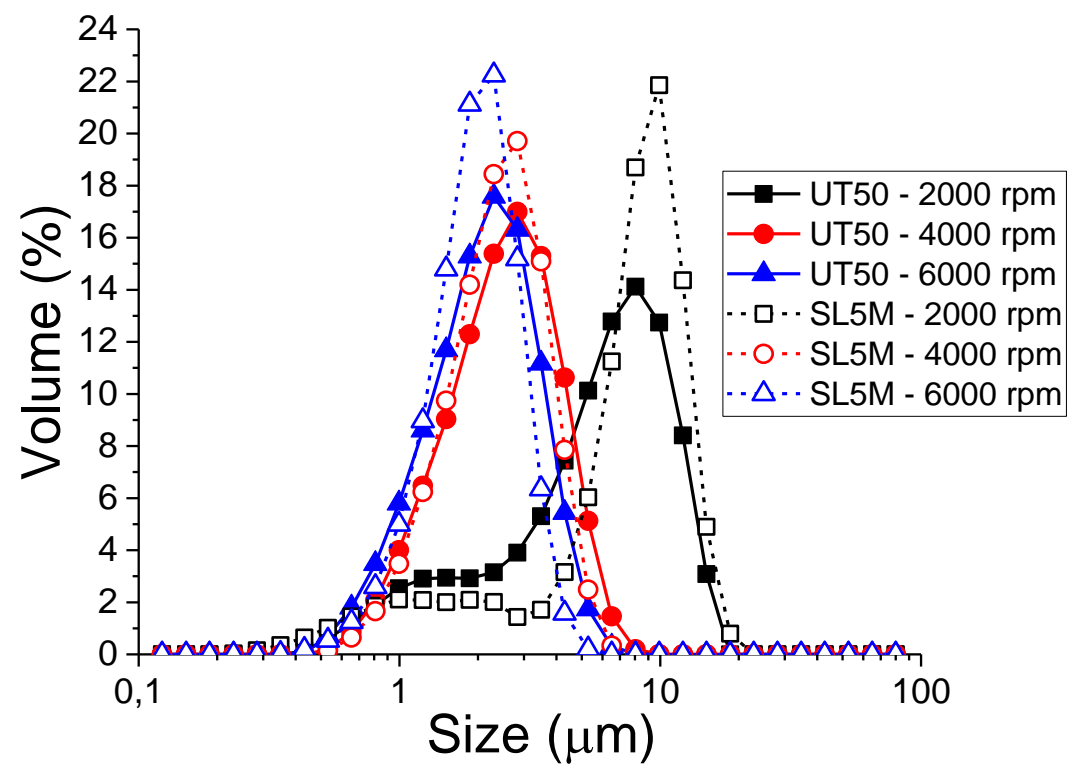

419 Figure 2. Droplet size distributions for pre-emulsions aged for 24 hours as a function of homogenization rate and rotor-stator device. 


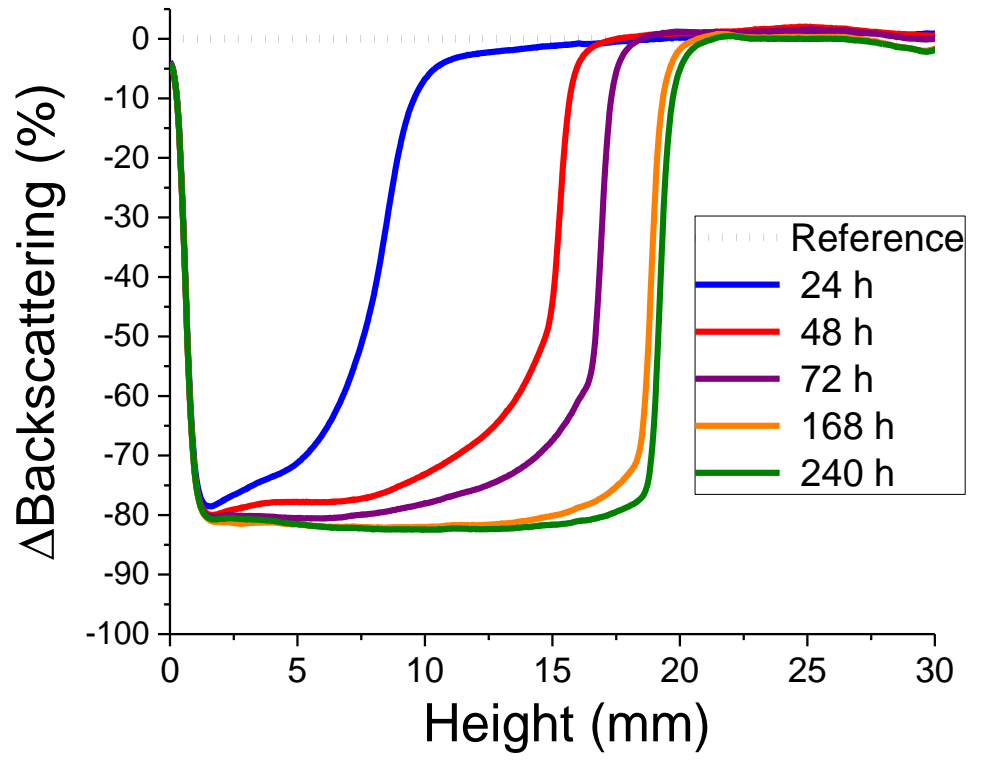

421

422 Figure 3. Backscattering versus container height as a function of aging time in reference 423 mode for the pre-emulsion processed with Silverson L5M at $2000 \mathrm{rpm}$. Temperature: 25 424 $\stackrel{\circ}{C}$

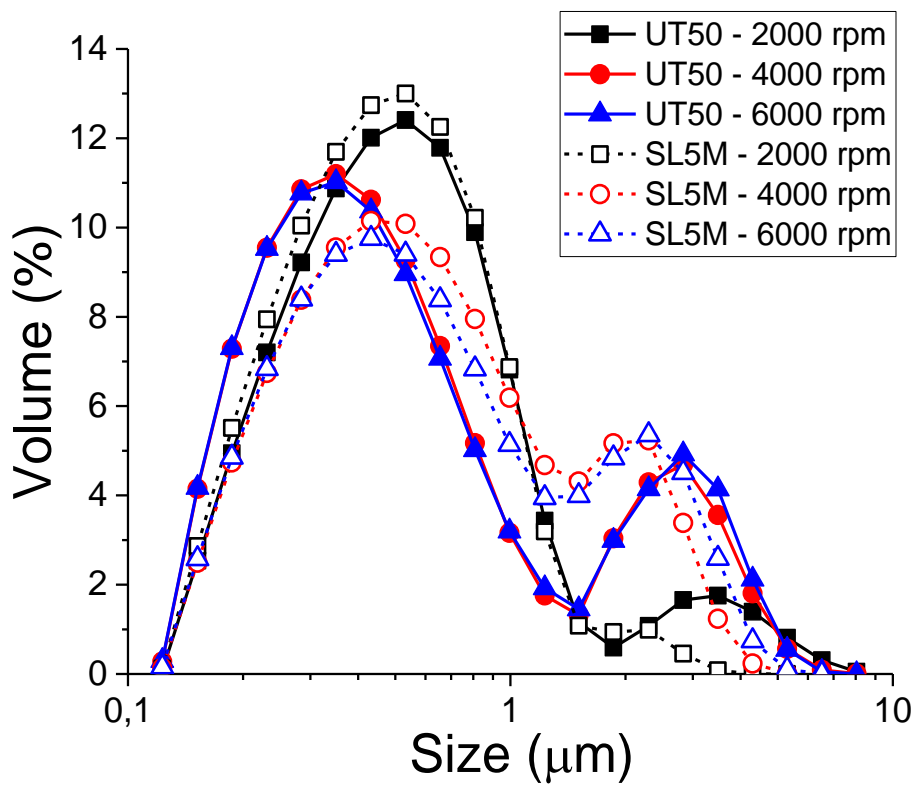

427 Figure 4. Droplet size distributions for final emulsions aged for 24 hours as a function of 428 homogenization rate and rotor-stator device used for the development of the pre429 emulsion. 


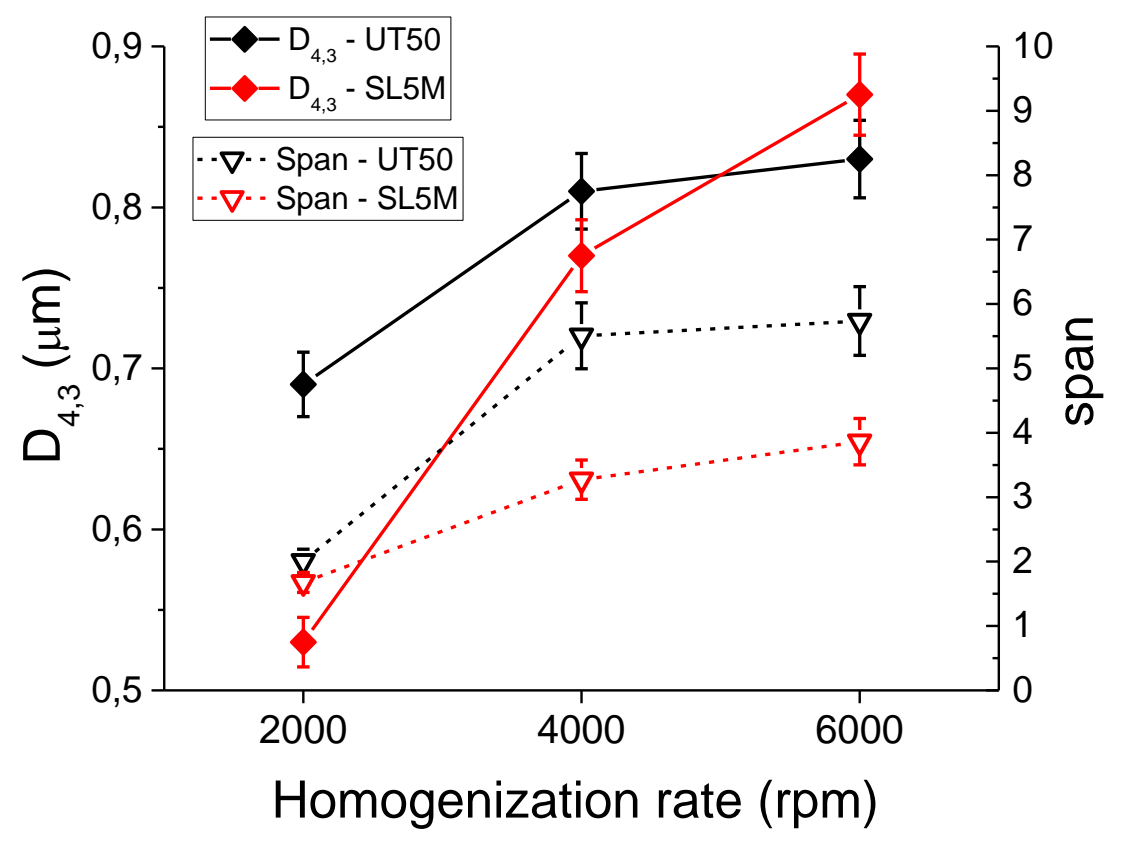

431 Figure 5. Volumetric mean diameters and span values as a function of homogenization 432 rate for final emulsions aged for 24 hours.

433

(A)

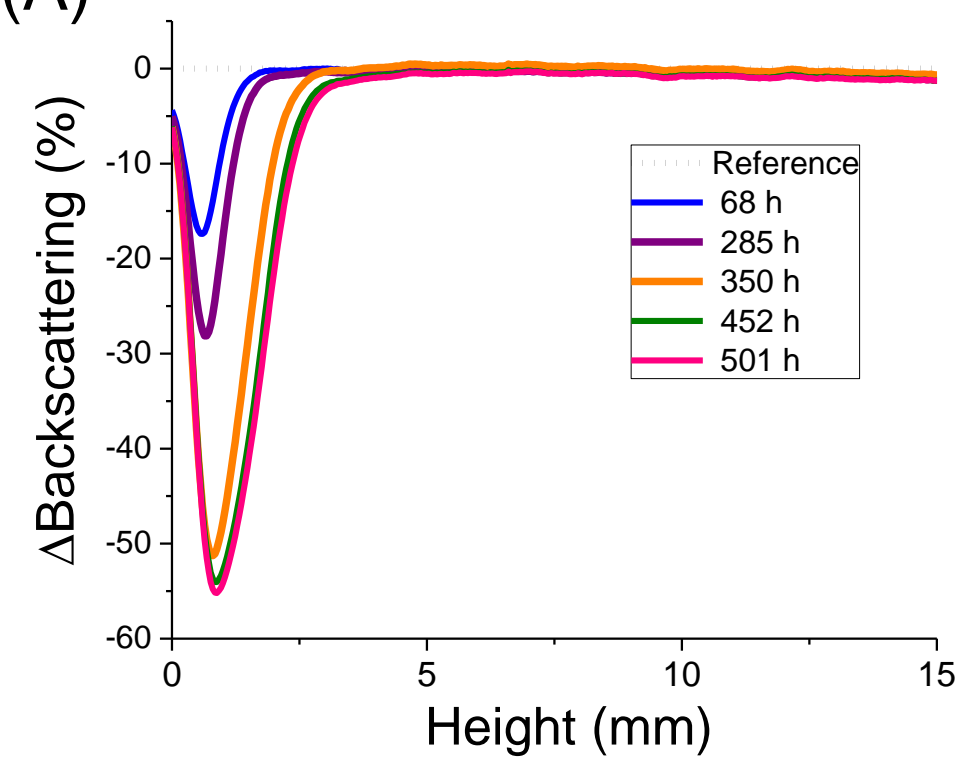




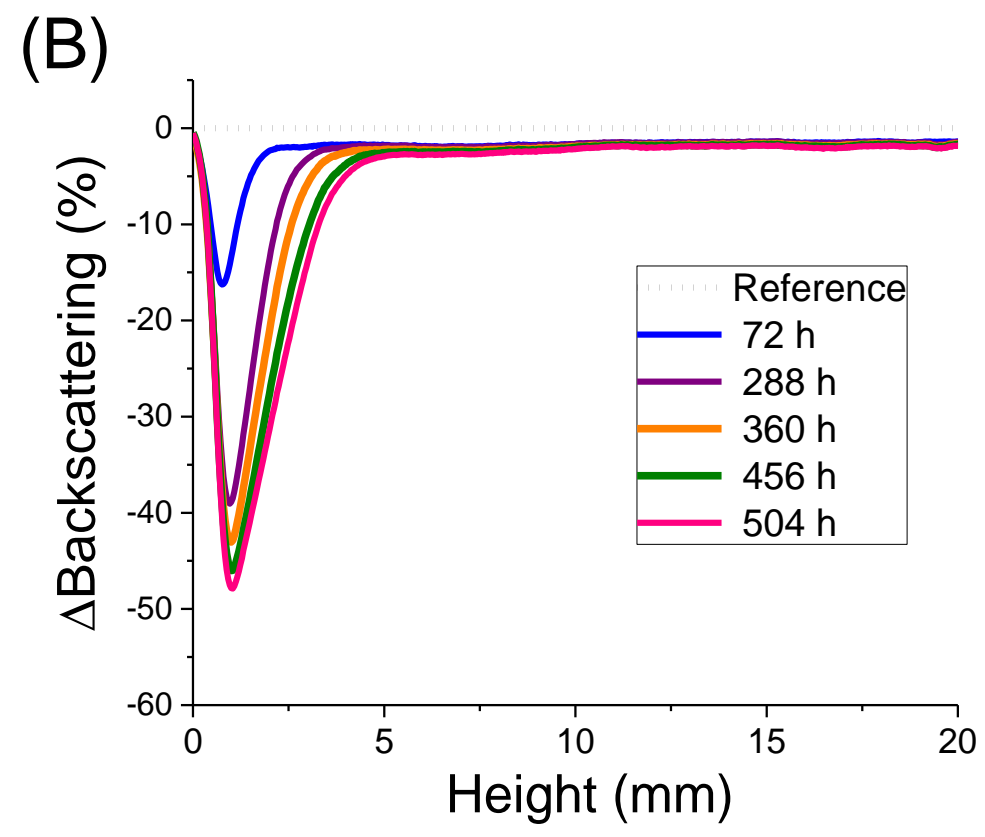

436 Figure 6. Backscattering versus container height as a function of aging time in reference 437 mode for final emulsions whose pre-emulsion was obtained with Ultraturrax T50 at (A) 438 $2000 \mathrm{rpm}$ and (B) $6000 \mathrm{rpm}$. Temperature: $25 \stackrel{\circ}{\mathrm{C}}$

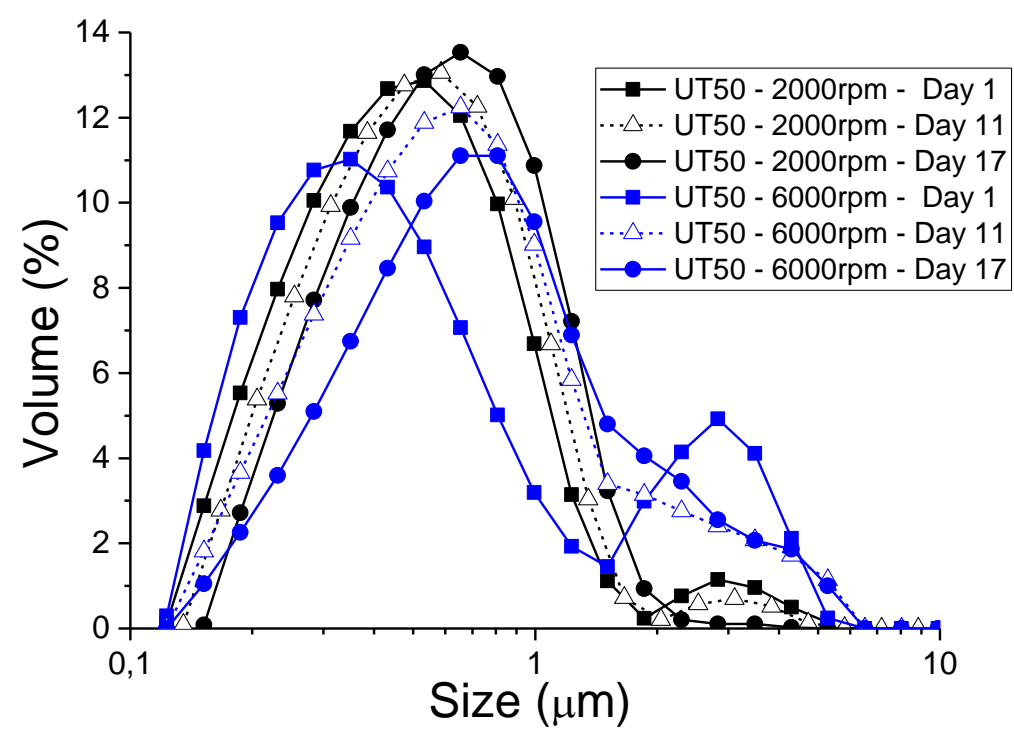

440 Figure 7. Droplet size distributions as a function of aging time for final emulsions whose 441 pre-emulsion was developed using Ultraturrax T50 at $2000 \mathrm{rpm}$ and $6000 \mathrm{rpm}$. 


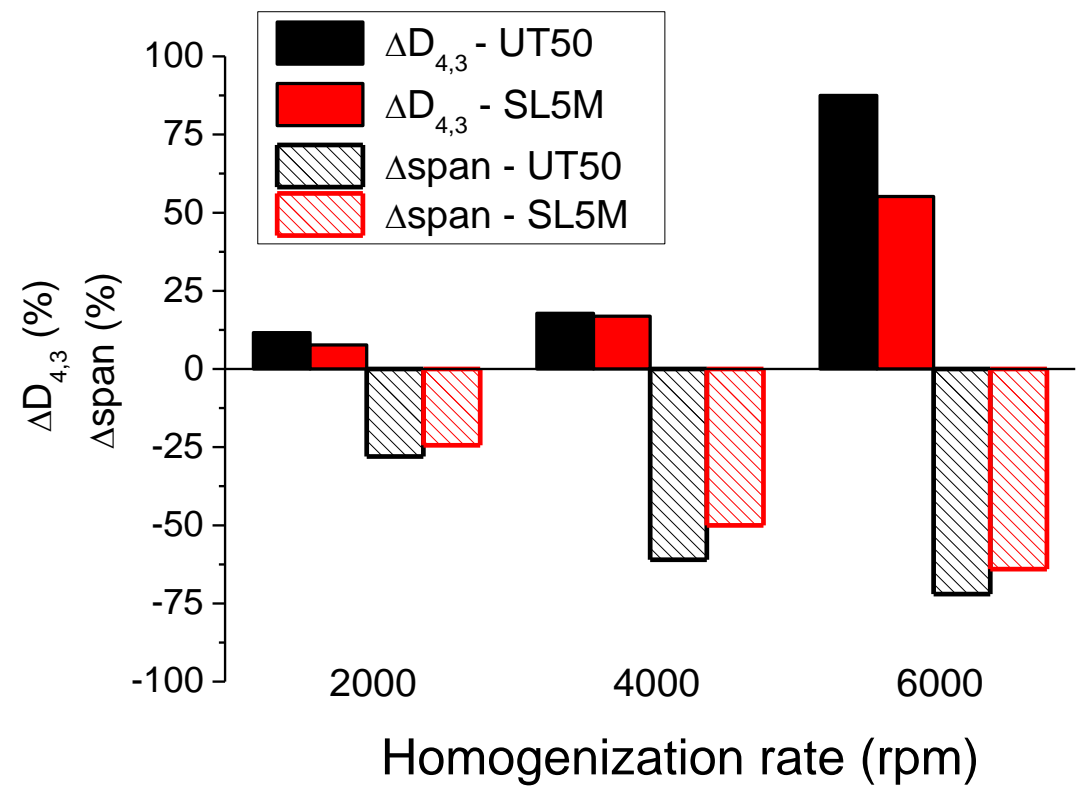

442

443 Figure 8. Variation of volumetric mean diameters and span values for final emulsions 444 between day 1 and day 20 as a function of the homogenization rate applied in the primary 445 homogenization.

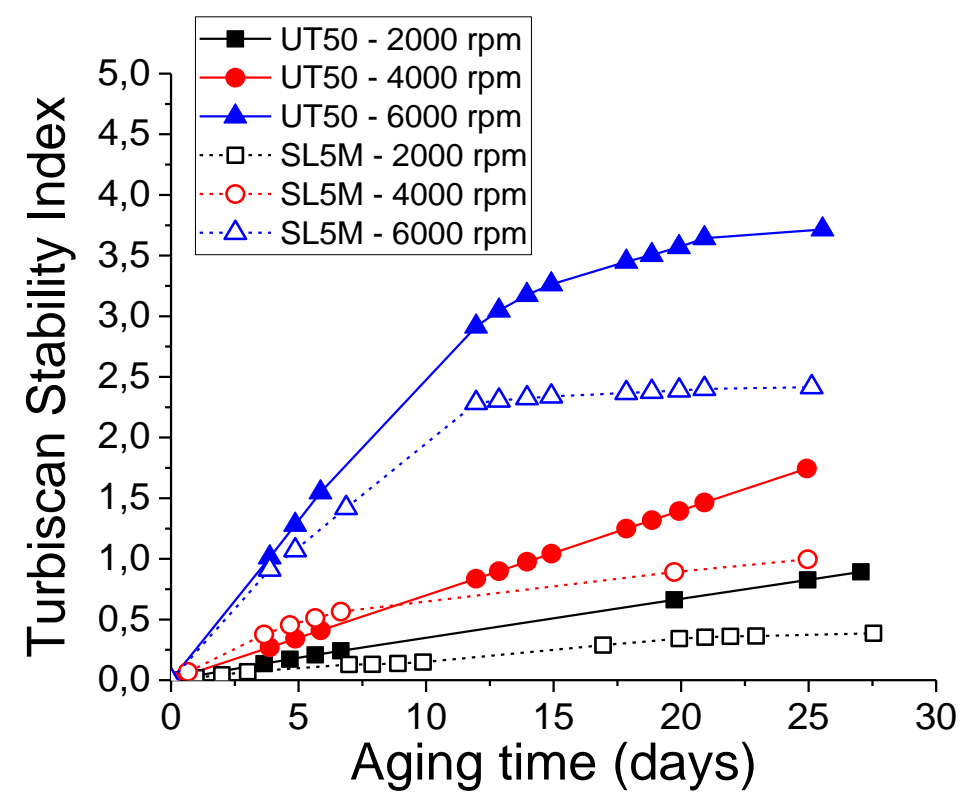

Figure 9. Turbiscan Stability Index of microfluidized emulsions as a function of aging 450 time. 